Technische

Universität

Berlin

Marko Jošt, Tobias Bertram, Dibyashree Koushik, Jose A. Marquez, Marcel A. Verheijen, Marc Daniel Heinemann, Eike Köhnen, Amran Al-Ashouri, Steffen Braunger, Felix Lang, Bernd Rech, Thomas Unold, Mariadriana Creatore, Iver Lauermann, Christian A. Kaufmann, Rutger Schlatmann, Steve Albrecht

\title{
21.6\%-efficient monolithic perovskite/Cu(In,Ga)Se2 tandem solar cells with thin conformal hole transport layers for integration on rough bottom cell surfaces
}

\author{
Open Access via institutional repository of Technische Universität Berlin \\ Document type \\ Journal article | Accepted version \\ (i. e. final author-created version that incorporates referee comments and is the version accepted for \\ publication; also known as: Author's Accepted Manuscript (AAM), Final Draft, Postprint)
}

This version is available at

https://doi.org/10.14279/depositonce-15187

\section{Citation details}

Jošt, M., Bertram, T., Koushik, D., Marquez, J. A., Verheijen, M. A., Heinemann, M. D., Köhnen, E., Al-Ashouri, A., Braunger, S., Lang, F., Rech, B., Unold, T., Creatore, M., Lauermann, I., Kaufmann, C. A., Schlatmann, R., \& Albrecht, S. (2019). 21.6\%-Efficient Monolithic Perovskite/Cu(In,Ga)Se2 Tandem Solar Cells with Thin Conformal Hole Transport Layers for Integration on Rough Bottom Cell Surfaces. In ACS Energy Letters (Vol. 4, Issue 2, pp. 583-590). American Chemical Society (ACS). https://doi.org/10.1021/acsenergylett.9b00135.

This document is the Accepted Manuscript version of a Published Work that appeared in final form in ACS Energy Letters, copyright $\odot$ American Chemical Society after peer review and technical editing by the publisher. To access the final edited and published work see https://doi.org/10.1021/acsenergylett.9b00135.

\section{Terms of use}

This work is protected by copyright and/or related rights. You are free to use this work in any way permitted by the copyright and related rights legislation that applies to your usage. For other uses, you must obtain permission from the rights-holder(s). 


\section{6\%-efficient monolithic perovskite/Cu(In,Ga)Se tandem solar cells with thin conformal hole transport layers for integration on rough bottom cell surfaces}

Marko Jošt ${ }^{1 *}$, Tobias Bertram², Dibyashree Koushik ${ }^{3}$, Jose A. Marquez ${ }^{4}$, Marcel A. Verheijen ${ }^{3,6}$, Marc Daniel Heinemann ${ }^{2}$, Eike Köhnen ${ }^{1}$, Amran Al-Ashouri ${ }^{1}$, Steffen Braunger ${ }^{1}$, Felix Lang ${ }^{5}$, Bernd Rech ${ }^{5}$, Thomas Unold ${ }^{4}$, Mariadriana Creatore ${ }^{3}$, Iver Lauermann ${ }^{2}$, Christian A. Kaufmann ${ }^{2}$, Rutger Schlatmann ${ }^{2,7}$, Steve Albrecht ${ }^{1,8}$

${ }^{1}$ Young Investigator Group Perovskite Tandem Solar Cells, Helmholtz-Zentrum Berlin für Materialien und Energie GmbH, Kekuléstraße 5, 12489 Berlin, Germany

${ }^{2} \mathrm{PV}$ comB, Helmholtz Zentrum Berlin für Materialen und Energie GmbH, 12489 Berlin, Germany

${ }^{3}$ Plasma and Materials Processing, Department of Applied Physics, Eindhoven University of Technology (TU/e), 5600 MB Eindhoven, The Netherlands

${ }^{4}$ Department of Structure and Dynamics of Energy Materials, Helmholtz-Zentrum-Berlin für Materialien und Energie GmbH, Hahn-Meitner Platz 1, 14109, Berlin, Germany

${ }^{5}$ Institute for Silicon Photovoltaics, Helmholtz-Zentrum Berlin für Materialen und Energie GmbH, 12489 Berlin, Germany

${ }^{6}$ Eurofins Materials Science BV, High Tech Campus 11, 5656 AE Eindhoven, the Netherlands

${ }^{7}$ Hochschule für Technik und Wirtschaft Berlin, Wilhelminenhofstrasse 75A, 12459 Berlin, Germany

${ }^{8}$ Technical University Berlin, Faculty IV - Electrical Engineering and Computer Science, Marchstraße 23, 10587 Berlin, Germany

*Corresponding author: marko.jost@helmholtz-berlin.de 


\section{Abstract}

Perovskite-based tandem solar cells have proven to be suitable candidates to increase the power conversion efficiency (PCE) of conventional single-junction photovoltaic devices, such as those based on silicon and $\mathrm{Cu}(\mathrm{In}, \mathrm{Ga}) \mathrm{Se}_{2}$ (CIGSe) absorbers, beyond the Shockley-Queisser single-junction PCE limit. Here, we present a highly efficient monolithic perovskite/CIGSe tandem solar cell with a solution processed perovskite top cell fabricated directly on an asgrown, rough $\mathrm{CIGSe}$ bottom cell. To prevent potential shunting due to the rough $\mathrm{CIGSe}$ surface, a thin $\mathrm{NiO}_{x}$ layer is conformally deposited via atomic layer deposition (ALD) on the ITO front contact of the CIGSe bottom cell. The performance is further improved by an additional layer of the p-type polymer PTAA at the $\mathrm{NiO}_{x} /$ perovskite interface. This novel hole transport bilayer enables a $21.6 \%$ stabilized PCE of the monolithic perovskite/CIGSe tandem device at $0.778 \mathrm{~cm}^{2}$ active area. We use TEM/EDX measurements to investigate the deposition uniformity and conformality of the $\mathrm{NiO}_{x}$ and PTAA layers. By comparing the performance of single-junction subcells with absolute photoluminescence measurements, we determine the contribution of the individual subcells to the tandem $V_{\text {oc }}$, revealing that further fine-tuning of the recombination layers between the two subcells might improve the tandem $V_{\text {oc }}$ further. Finally, based on the obtained results we give guidelines on how to further improve monolithic perovskite/CIGSe tandems towards predicted PCE estimates above $30 \%$.

\section{Graphical table of contents:}

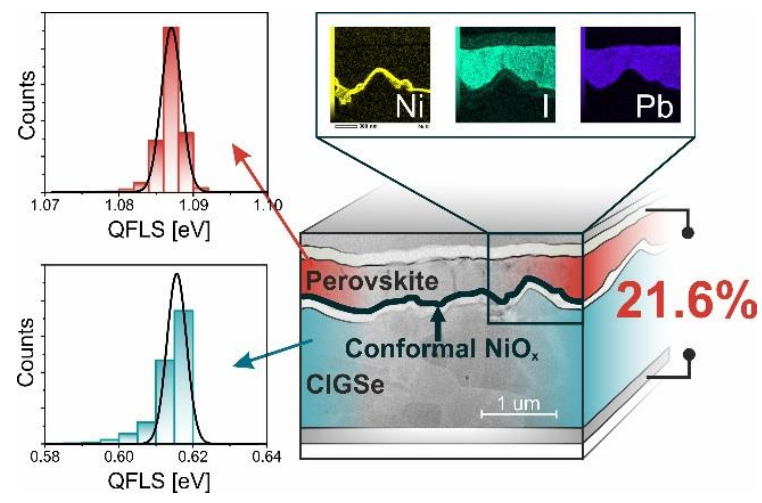


Perovskite solar cells have recently attracted much interest in the photovoltaic community due to the ease of their fabrication and ability to tune their properties through composition and interface engineering. ${ }^{1-4}$ This resulted in a steep rise in power conversion efficiencies (PCE) to over $23 \%$ in $2018 .{ }^{5} \mathrm{~A}$ further increase of PCE to $>30 \%$ could be realized by tandem devices utilizing perovskite as wide bandgap top cell in combination with existing technologies, such as silicon, perovskites, or copper indium gallium selenide $\left(\mathrm{Cu}(\mathrm{In}, \mathrm{Ga}) \mathrm{Se}_{2}-\mathrm{CIGSe}\right)$ as low band gap bottom cell. ${ }^{6-8}$ To implement a top cell that is fabricated by wet chemical methods such as spin-coating in a monolithic (2-terminal) stack, flat bottom cells are the substrates of choice for easy processing. Consequently, the reported highest tandem PCEs in monolithic configuration have mostly been achieved using perovskite combined with polished crystalline silicon as bottom cell. ${ }^{9-11}$ One remaining challenge is the fabrication of perovskite top cells on textured surfaces, such as pyramidal etched silicon ${ }^{12}$ or rough CIGSe, which is the focus of the study reported in this paper.

CIGSe solar cells have a bandgap of around $1.1 \mathrm{eV}$, which is perfect for efficient tandem performance when combined with a larger bandgap perovskite top cell. The best CIGSe standalone single-junction solar cell devices reach a PCE of $22.9 \% .^{5}$ Due to the direct bandgap of CIGSe and the resulting significantly reduced absorber thicknesses, the technology enables low material and energy consumption. A combination of perovskite and CIGSe could enable a fully thin-film tandem technology with high PCE at low costs. Furthermore, just like perovskite, chalcogenide compositions can be tuned to manipulate the precise band gap to enable current matching in the tandem architecture. ${ }^{13}$ First tandem solar cells with CIGSe bottom cells in a 4terminal configuration have already been presented in $2015 .{ }^{14,15}$ In this configuration, the perovskite standalone top cell is mechanically stacked on top of the standalone CIGSe bottom cell. Fabricating both subcells independently from each other has enabled the rise in PCE of tandem solar cells in recent years essentially by improving the performance of the perovskite cell. Fu et al. have shown up to $22.1 \% \mathrm{PCE}^{16}$ in 2015 by utilizing a less absorbing $\mathrm{p}$-i-n configuration. The current record for 4-terminal configurations of $23.9 \%$ was recently published by Shen et al. and enabled by widening of the perovskite bandgap to $1.62 \mathrm{eV} .{ }^{8}$

On the other hand, the fabrication of a monolithic perovskite/CIGSe tandem has proven to be very challenging, and up to now only a few reports can be found. One of the main reasons might lie in relatively rough CIGSe morphology. A surface root mean square $\left(\sigma_{\mathrm{RMS}}\right)$ roughness of a typical CIGSe layer is in the range of $50-200 \mathrm{~nm}$, with typical lateral feature sizes in the order of $500 \mathrm{~nm}$ to $1 \mu \mathrm{m}$, depending on the details of the processing. ${ }^{17,18}$ Consequently, depositing a perovskite top cell and especially its very thin selective contacts from solution, which is to date the most common and efficient way of perovskite fabrication, $3,4,19$ is not possible without a high probability of shunting the top cell in the tandem device. The first monolithic perovskite/CIGSe tandem device reported possessed a PCE of $11 \%,{ }^{20}$ enabled by a thick PEDOT:PSS hole selective layer between top and bottom cell. While a thicker PEDOT:PSS layer protected the top cell from shunting, the overall tandem cell performance might have suffered from reduced $V_{O C}$ at the PEDOT:PSS/perovskite interface. ${ }^{21}$ Alternatively, to fabricate an efficient monolithic device, new approaches of fabricating the bottom cells suitable for monolithic tandem cells are needed. Fabricating copper indium di-selenide (CIS) by electrodeposition or spin-coating resulted in a smoother bottom cell surface and enabled 
monolithic tandem solar cell PCEs of $11.0 \%$ and $8.55 \%$, respectively. ${ }^{22,23}$ Recently, however, Han et al. presented a new solution as used in perovskite/silicon devices, where the front surface of the interconnection layers on top of the CIGSe bottom cell was polished to reduce roughness. In this way, the spin-coating of perovskite and very thin contact layers can be implemented without losses due to surface roughness. Consequently, a record PCE of $22.4 \%$ was obtained. ${ }^{24}$ Nevertheless, this approach of an additional polishing step might not be favorable for industrial application on large areas and requires very thick interconnection layers that induce losses due to parasitic absorption. Furthermore, the rougher surface, if translated to the front of the device, might lead to beneficial light trapping effects.

In this communication, we present a monolithic perovskite/CIGSe tandem solar cell utilizing a CIGSe bottom cell with the typical roughness mentioned above and without any posttreatment. Instead, we implement the hole contact of the perovskite top cell, grown conformally on top of the front contact of the CIGSe bottom cell. This is achieved by a $10 \mathrm{~nm}$ thick atomic layer deposited (ALD) $\mathrm{NiO}_{x}$, capable of preventing shunting of the top cell. As the $\mathrm{NiO}_{x} /$ perovskite interface is known to be limited in $V_{\text {oc }}$ by interface recombination more than e.g. polymeric based charge transport layers, ${ }^{4,25,3,26}$ the $\mathrm{NiO}_{x}$ interface is further optimized by introducing an additional layer of the polymer poly [bis(4-phenyl)(2,4,6trimethylphenyl)amine] (PTAA). Thus, a p-type selective contact bilayer is introduced, leading to a monolithic perovskite/CIGSe tandem device with a stabilized PCE of $21.6 \%$ in maximum power point tracking over 10 minutes. The bilayer-based tandem device shows a superior performance as compared to a tandem cells with a $\mathrm{NiO}_{x}$-only hole transport layer, which achieved $18 \%$ stabilized PCE only. The conformal growth of the ALD NiO $x$ is confirmed by TEM and EDX measurements, highlighting elemental distribution. The absorber quality of both subcells is investigated by means of absolute photoluminescence (PL). With the help of absolute PL measurements, the Quasi-Fermi level splitting (QFLS) from each subcell is determined and with that the contribution to the tandem $V_{O C}$ is quantified. A difference of $100 \mathrm{mV}$ between the QFLS and the tandem $V_{\text {oc }}$ points to the interconnecting $\mathrm{ZnO}$ recombination layer as a component that allows further optimization. Following this, we present a detailed loss analysis and guidelines for further possible improvements.

The layout of the fabricated device is presented in Figure 1, superimposed on a High Angle Annular Dark Field (HAADF) - scanning transmission electron microscope (STEM) cross section image. The bottom cell is fabricated on glass in substrate configuration with molybdenum as back electrode. Then the CIGSe layer is deposited by a 3-stage evaporation as described in, ${ }^{18}$ which results in rough films with a thickness in the range of $2.5 \mu \mathrm{m}$. The bottom cell is completed in a standard process sequence with a $\mathrm{CdS}$ buffer layer and an intrinsic/aluminum doped $\mathrm{ZnO}$ (i-ZnO/ZnO:Al) bilayer as recombination contact for our tandem device. Such a stack was then used as a substrate for the top cell fabrication. Due to the typical polarity of a CIGSe device, we select a $\mathrm{p}-\mathrm{i}-\mathrm{n}$ (so called "inverted") perovskite top cell architecture. Typical hole transporting layers (HTL) in perovskite $p$-i-n configurations are polymers, such as polyTPD, ${ }^{27}$ PTAA, ${ }^{3,28}$ PEDOT:PSS ${ }^{29}$ or metal-oxides such as $\mathrm{NiO}_{x}{ }^{26,30,31}$ These materials can be processed via spin-coating utilizing a wet-chemical process, yielding a final thickness in the order of several tens of $\mathrm{nm}$. However, using this deposition process, this thickness is not enough to uniformly coat the rough bottom cell surfaces with a $\sigma_{\text {RMS }}$ of $\sim 75 \mathrm{~nm}$ and thus 
results in shunted devices. To produce a conformal HTL on top of the rough bottom cell surface, we utilized $\mathrm{NiO}_{x}$ that was fabricated via ALD. ${ }^{32,33}$ This resulted in a uniformly covered surface, even on rough morphologies (see Figure 2), thus preventing a direct contact between the perovskite and $\mathrm{ZnO}: \mathrm{Al}$. Our initial tests showed that for optimum performance of $\mathrm{NiO}_{\mathrm{x}}$ deposited via ALD a post-annealing step of $300^{\circ} \mathrm{C}$ is needed. However, such high temperatures are not suitable for completed CIGSe devices due to interdiffusion at the CIGSe/CdS interface. Therefore, the $\mathrm{NiO}_{x}$ was adopted as pristine layer here without post annealing. Despite

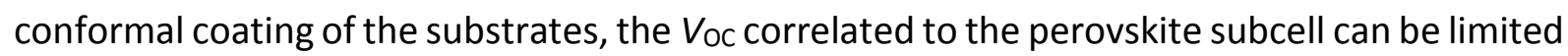
when only $\mathrm{NiO}_{x}$ was used as HTL for the perovskite top cell $25,26,30,33$. Potentially, the $V_{\text {oc }}$ could be increased under light soaking due to lattice expansion or defect passivation of the perovskite absorber. ${ }^{26,34}$ However, in our case we increased the $V_{0 c}$ by spin-coating a thin layer of the p-type polymer PTAA on top of the $\mathrm{NiO}_{x}$ layer, probably due to a reduction of recombination at the $\mathrm{HTL} /$ perovskite interface (see section below). This bilayer of ALD $\mathrm{NiO}_{\mathrm{x}}$ and PTAA proved to be an elegant way for the fabrication of efficient tandem solar cells. For the perovskite layer, a multiple cation, multiple halide (so called "triple cation") composition, $\mathrm{Cs}_{0.05}\left(\mathrm{MA}_{0.17} \mathrm{FA}_{0.83}\right) \mathrm{Pb}_{1.1}\left(\mathrm{I}_{0.83} \mathrm{Br}_{0.17}\right)_{3}$, where $\mathrm{MA}$ and $\mathrm{FA}$ are methylammonium and formamidinium cations, was chosen..$^{35}$ This formulation can be spin-coated on top of the rough surface as the obtained absorber layer thickness is larger than the peak to valley distance of the bottom cell. The tandem device is finished by utilizing a top contact that was developed and optimized for perovskite/silicon tandem solar cells. ${ }^{11}$ The top contact stack is formed by depositing $\mathrm{C}_{60}$ by evaporation, tin oxide $\left(\mathrm{SnO}_{2}\right)$ by ALD and indium zinc oxide (IZO) as a front contact by sputtering. The tandem solar cell is finished by evaporating a metal frame around the active area, slightly covering the IZO, and LiF as an anti-reflection coating. The top perovskite solar cell then has a final layer configuration of $\mathrm{NiO}_{x} / \mathrm{PTAA} /$ perovskite/ $\mathrm{C}_{60} / \mathrm{SnO}_{2} / \mathrm{IZO} / \mathrm{LiF}$ as depicted in Figure 1 . The detailed fabrication process can be found in the experimental section.

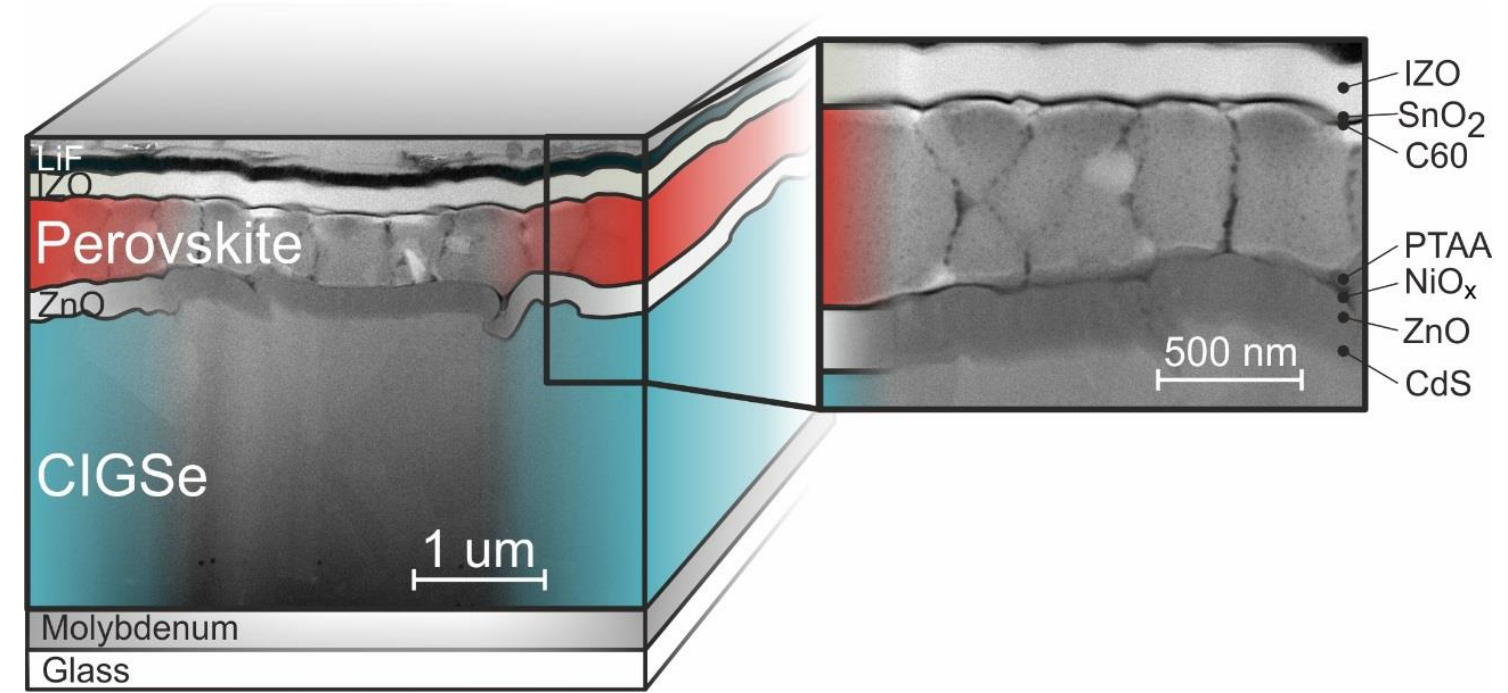

Figure 1: Schematic of a monolithic perovskite / CIGSe tandem superimposed on a HAADF-STEM cross-section image with all the layers depicted. The inset displays the perovskite top cell in more detail. Additional top cell STEM images with material composition analysis from EDX measurements are shown in Figure 2.

Figure 1 highlights the zoomed-in cross sectional HAADF-STEM image of the fabricated tandem solar cell. The obtained perovskite grains are in the range of a few $100 \mathrm{~nm}$ and well 
defined, despite the non-flat surface base of the CIGSe layer that can clearly be observed. The $\sigma_{\mathrm{RMS}}$ of the $\mathrm{ZnO}$ :Al bottom cell surface obtained from the AFM is $\sim 75 \mathrm{~nm}$, which is much higher than for typical ITO ( 3 nm) or FTO $(\sim 15 \mathrm{~nm})$ coated glass substrate surfaces. Spin-coating on such a rough surface produces a highly inhomogeneous layer thickness as shown by TEM and EDX measurements of the cross section (Figure 2). In Figure 2 we analyze in more detail a larger grain of the CIGSe absorber, which sticks out of the surrounding, being a potential cause of a shunt when spin-coating thin layers on top. Figure 2a shows the transmission electron microscopy (TEM) image, while the energy-dispersive X-ray spectroscopy (EDX) maps in b-g represent the elemental composition of the layers, trying to determine the surface coverage of the thin layers. The figures were selected to highlight the properties of the bilayer p-type contact utilized here. From Figure $2 \mathrm{~b}$, clearly a conformal coating of the interconnecting $\mathrm{ZnO}$ layer is seen by the homogeneous zinc $(\mathrm{Zn})$ distribution of the ca. $150 \mathrm{~nm}$ thick $\mathrm{ZnO}$ layer, as expected for the sputter coating. From Figure $2 \mathrm{c}$ a distinct, conformal and homogeneous $\mathrm{NiO}_{\mathrm{x}}$ layer with ca. $10 \mathrm{~nm}$ thickness on top of the interconnecting $\mathrm{ZnO}$ can be identified. This is rather important as only $10 \mathrm{~nm} \mathrm{NiO}$ formed via ALD is enough to protect the perovskite from direct contact to the interconnecting ITO. Figure $2 \mathrm{~d}$ shows the carbon signal to identify the polymeric PTAA layer. Unfortunately, the carbon is not easily detectable by EDX due to the detection limit. However, as also visible in the TEM image Figure 2a (see darker areas in the valley, marked by arrows), this layer is not uniform in thickness throughout the rough surface. Typically, 8-12 nm PTAA is formed on flat surfaces with the processing conditions applied here, however, on a rough surface the thickness changes. A negligible thickness can be found on the peak while layer agglomeration can be observed in the valley. To further emphasize this, we show in Figure S1 the equivalent sample, where the bilayer was deposited on an even rougher surface. There we focus on a distinct valley and peak areas. Again the $\mathrm{NiO}_{x}$ covers the surface conformally, for both peak and valley areas. For PTAA, on the other hand, a negligible thickness can be found close to the edges of the valley while up to $60 \mathrm{~nm}$ thickness can be found at the bottom. On the peak, no distinct carbon signal was observed. Here, we would also like to point out that the non-homogeneous PTAA layer might contribute to improved film formation conditions for perovskite crystallization due to slight flattening of the surface. Our TEM results demonstrate that solely spin-coating is not suitable for such rough surfaces. However, other deposition techniques, such as sputtering ( $\mathrm{Zn}-\mathrm{ZnO}$, In - IZO), ALD ( $\mathrm{Ni}-\mathrm{NiO}_{x}$, $\left.\mathrm{Sn}-\mathrm{SnO}_{2}\right)$ and chemical bath deposition $(\mathrm{Cd}-\mathrm{CdS})$ cover the surface conformally. 
a)

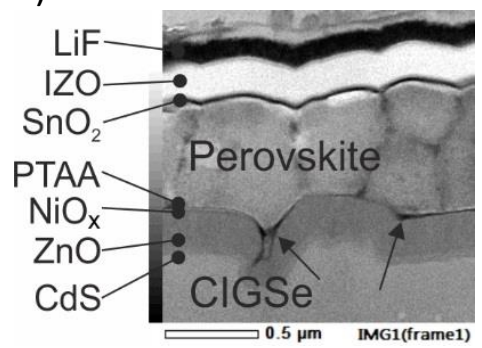

b) $\mathrm{Zn}$

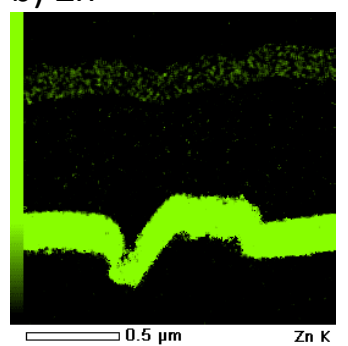

e) $\mathrm{Cd}$

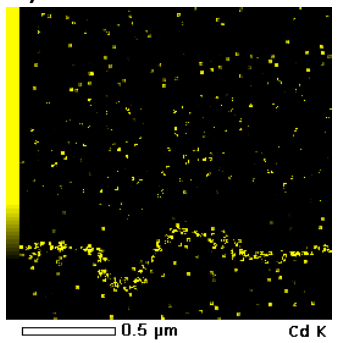

c) $\mathrm{Ni}$

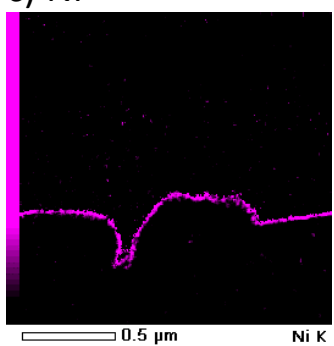

f) $\mathrm{Sn}$

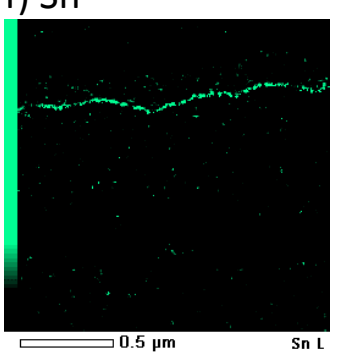

d) C

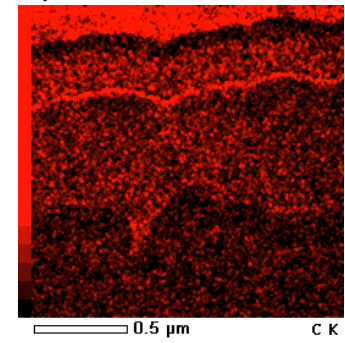

g) In

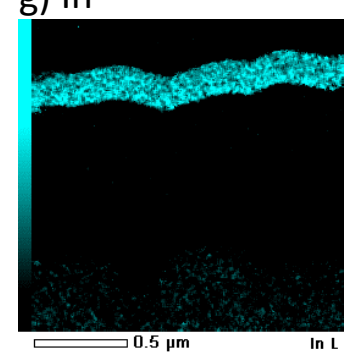

Figure 2: Cross sectional HAADF-STEM images (a) and elemental maps (b-g) deduced from EDX measurements of the fabricated tandem device with a focus on the perovskite top cell. a) STEM of a peak-valley-shaped region, where depletion and agglomeration of PTAA is visible (see arrows), confirmed by an increased carbon signal in the EDX image d). Ni (violet) on the other hand covers both the valley and the peak conformally. Zinc is depicted by green, Ni violet, carbon (PTAA) red, cadmium yellow, tin turquoise and indium cyan color.

Figure $3 a$ shows the $J-V$ characteristics of the monolithic tandem solar cells under AM $1.5 \mathrm{G}$ illumination with three different HTLs: PTAA, $\mathrm{NiO}_{x}$ and $\mathrm{NiO}_{x} /$ PTAA bilayer. The active area of devices is $0.81 \mathrm{~cm}^{2}$, further masked to have an illuminated area of $0.778 \mathrm{~cm}^{2}$. First, the PTAA-only tandem device is characterized by a strongly limited efficiency with indications for shunting, thus showing that spin-coating a thin layer of PTAA is not suitable for rough CIGSe surfaces and confirming the need for a conformal deposition of the HTL. Secondly, the $\mathrm{NiO}_{x}$-only device already performs well with $18.0 \%$ PCE in maximum power point (MPP) tracking (Figure S2), fitting well with the value obtained from the $J-V$ scan. Nevertheless, the device is limited by a low $V_{0 C} \sim 1.5 \mathrm{~V}$ and $\mathrm{FF} 70 \%$. Finally, a remarkable PCE of $21.6 \%$ is measured for the $\mathrm{NiO}_{x} /$ PTAA HTL bilayer, which, to the best of our knowledge, is the highest PCE reported for a perovskite/CIGSe tandem solar cell with an area larger than $0.2 \mathrm{~cm}^{2}$ $\left(0.778 \mathrm{~cm}^{2}\right.$ for our device). The high PCE was enabled by high short-circuit current density $J_{S C}$ of $18.0 \mathrm{~mA} \mathrm{~cm}^{-2}$ and excellent $\mathrm{FF}$, exceeding $75 \%$. The open-circuit voltage $V_{\mathrm{Oc}}$, at $1.59 \mathrm{~V}$ is still below the values from perovskite/silicon tandem solar cells and a parameter for future improvement. All the parameters have similar values independent of the scan direction (reverse $\left(V_{\mathrm{OC}}\right.$ to $\left.J_{\mathrm{SC}}\right)$ and forward $\left(J_{\mathrm{SC}}\right.$ to $\left.V_{\mathrm{OC}}\right)$ ), showing little to no hysteresis. The MPP PCE is stable at $21.6 \%$ during the 10 minute tracking (see inset in Figure 3a). The main difference between the $\mathrm{NiO}_{x}$-only and $\mathrm{NiO}_{x} /$ PTAA devices is in lower $\mathrm{V}_{\mathrm{OC}}$ and FF of the $\mathrm{NiO}_{x}$-only device, pointing to the limiting $\mathrm{NiO}_{x}$ /perovskite interface, especially when considering that both devices were prepared in exactly the same way, except for the additional PTAA layer. The issue will also be briefly discussed below. All the performance parameters are summarized in Table 1.

The photocurrent contribution from each subcell of a $\mathrm{NiO}_{x} /$ PTAA bilayer tandem device was further analyzed by EQE and reflectance measurements (1-R depicted) as shown in Figure $3 \mathrm{~b}$. The EQE spectra of the perovskite and CIGSe subcells were measured independently and the 
corresponding photocurrent values, when assuming AM 1.5G illumination, are presented. The photocurrents of the two subcells are strongly mismatched $\left(\sim 2 \mathrm{~mA} \mathrm{~cm}{ }^{-2}\right)$, leaving some room for the improvement by fine-tuning the perovskite bandgap or its thickness for current matching. The 1-R spectrum shows that only $2.62 \mathrm{~mA} \mathrm{~cm}^{-2}$ are lost in the device due to reflection. This is a rather low value and could be caused by rough interfaces in the device, which improve the light management and consequently reduces total reflection, as indicated in the introductory section. The small difference between EQE and 1- $R$ spectra reveals minimal losses due to parasitic absorption in the range between 400 and $1000 \mathrm{~nm}$, enabled by a highly transparent n-type top contact. In the UV and infra-red region the parasitic absorption is higher due to absorption in $\mathrm{C}_{60}$ and IZO, limited CIGSe absorption near its bandgap and free carrier absorption in ZnO. Nevertheless, all this indicates already excellent optical performance of our tandem solar cell, which could be further improved by reducing the current mismatch between the two subcells or by proper light management from e.g. textured foils as previously shown for perovskite single-junction cells ${ }^{36}$ or perovskite/silicon tandem cells. ${ }^{11}$

a)

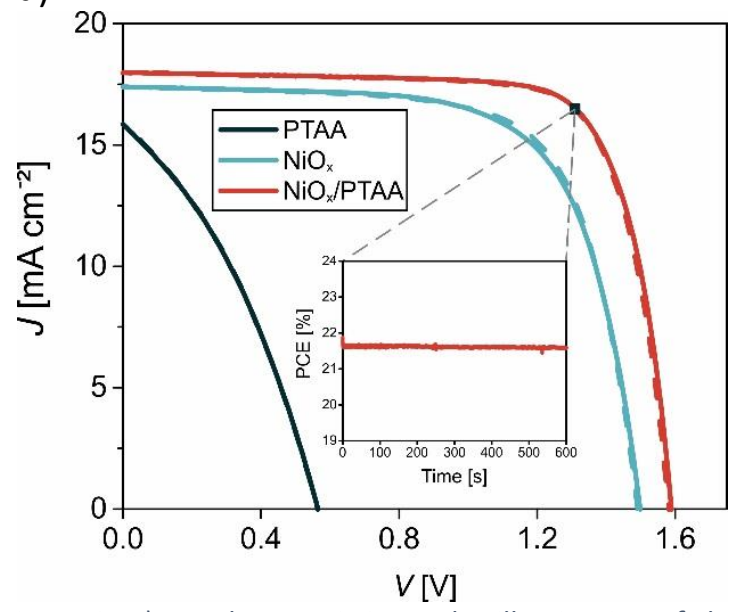

b)

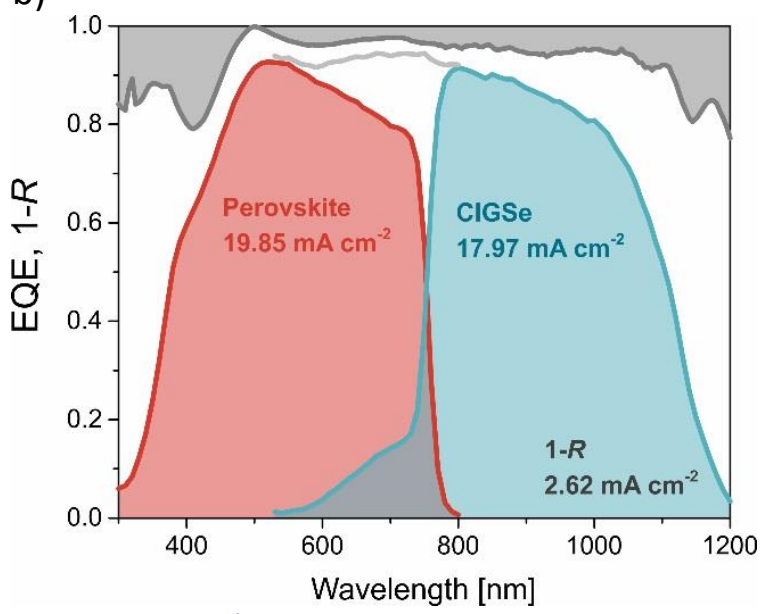

Figure 3: a) J-V characteristics under illumination of the monolithic perovskite/CIGSe tandem solar cell. Solid line shows forward ( $J_{S c}$ to $V_{O C}$ ) scan and dashed line reverse ( $V_{o c}$ to $J_{S C}$ ) scan direction. Three different HTLs are investigated, PTAA (black), $\mathrm{NiO}_{x}$ (blue) and NiO $\mathrm{N}_{x}$ PTAA (red). The MPP tracking over $10 \mathrm{~min}$ of the NiO $\mathrm{X}_{x} / \mathrm{PTAA}$ device is shown as an inset. b) EQE spectra of the NiO^/PTAA tandem device measured for the individual subcells and the total reflection spectra depicted as 1-R. Perovskite, CIGSe and 1-R spectra are denoted with red, blue and gray lines and areas. Integrated photocurrents and reflection losses from EQE and 1-R spectra values are also shown.

Despite the promising integration of the thin conformal $p$-type contact directly on top of the rather rough CIGSe bottom cell, the tandem device performance is below theoretical limits, especially when $V_{o c}$ is considered. To analyze this in more detail, single-junction devices, corresponding to both subcells, were fabricated and tested. Figure 4a shows the CIGSe reference cell which was finished with a $\mathrm{Ni} / \mathrm{Al} / \mathrm{Ni}$ metal grid as front contact. The solar cell device reached a PCE of $16.3 \%$. Further improvements in PCE are possible by alkali postdeposition treatment, improving the $V_{\mathrm{OC}}$, and by efficient light trapping (e.g. anti-reflection coating), improving the $J_{\text {sc. }}$. We have also measured the CIGSe single-junction device under reduced light intensity, imitating the current that is generated in the tandem device. A significantly reduced $V_{O C}(\sim 30 \mathrm{mV})$ was measured for the CIGSe device, showing that the low intensity response needs to be analyzed in more detail. 
Table 1: Performance parameters of the monolithic perovskite/CIGSe tandem solar cell, the standalone CIGSe reference cell and standalone perovskite reference cell with different hole transporting layers. The J-V characteristics under illumination of the tandem cell is shown in Figure 3a, while the J-V characteristics of the reference single-junction cells are shown in Figure 4. For the reduced intensity measurement the light intensity was attenuated until the CIGSe single-junction device generated approximately the same current as the bottom cell in the tandem device.

\begin{tabular}{|c|c|c|c|c|c|c|c|}
\hline & & $\begin{array}{c}\text { Scan } \\
\text { direction }\end{array}$ & $\begin{array}{c}J_{\mathrm{sc}} \\
{\left[\mathrm{mA} \mathrm{cm}^{-2}\right]}\end{array}$ & $\begin{array}{l}V_{\text {oc }} \\
{[V]}\end{array}$ & $\begin{array}{c}\mathrm{FF} \\
{[\%]}\end{array}$ & $\begin{array}{l}\text { PCE } \\
{[\%]} \\
\end{array}$ & $\begin{array}{c}\mathrm{PCE}_{\mathrm{MPP}} \\
{[\%]}\end{array}$ \\
\hline \multirow[t]{6}{*}{ Tandem } & \multirow[t]{2}{*}{ PTAA } & $J_{\mathrm{SC}}$ to $V_{\mathrm{OC}}$ & 15.9 & 0.56 & 34.9 & 3.1 & \\
\hline & & $V_{\mathrm{OC}}$ to $J_{\mathrm{SC}}$ & 15.9 & 0.56 & 35.0 & 3.1 & \\
\hline & \multirow[t]{2}{*}{$\mathrm{NiO}_{x} /$ PTAA } & $J_{S C}$ to $V_{O C}$ & 18.0 & 1.58 & 76.0 & 21.6 & \multirow[t]{2}{*}{$21.6 \%$} \\
\hline & & $V_{\mathrm{OC}}$ to $J_{\mathrm{SC}}$ & 18.0 & 1.59 & 75.7 & 21.6 & \\
\hline & \multirow[t]{2}{*}{$\mathrm{NiO}_{x}$} & $J_{S C}$ to $V_{O C}$ & 17.4 & 1.49 & 70.2 & 18.2 & \multirow[t]{2}{*}{$18.0 \%$} \\
\hline & & $V_{\mathrm{OC}}$ to $J_{\mathrm{SC}}$ & 17.4 & 1.50 & 68.4 & 17.8 & \\
\hline ClGSe & \multicolumn{2}{|l|}{ AM1.5G } & 35.8 & 0.65 & 70.6 & 16.3 & \\
\hline \multicolumn{3}{|c|}{ Reduced intensity } & 18.3 & 0.62 & 72.2 & 8.2 & \\
\hline \multirow[t]{6}{*}{ Perovskite } & \multirow[t]{2}{*}{ PTAA } & $J_{S C}$ to $V_{O C}$ & 20.5 & 1.10 & 77.6 & 17.5 & \\
\hline & & $V_{\mathrm{OC}}$ to $J_{\mathrm{SC}}$ & 20.6 & 1.10 & 77.9 & 17.6 & \\
\hline & \multirow[t]{2}{*}{$\mathrm{NiO}_{x} /$ PTAA } & $J_{S C}$ to $V_{O C}$ & 20.4 & 1.09 & 74.8 & 16.7 & \\
\hline & & $V_{\mathrm{OC}}$ to $J_{\mathrm{SC}}$ & 20.4 & 1.09 & 75.2 & 16.7 & \\
\hline & \multirow[t]{2}{*}{$\mathrm{NiO}_{x}$} & $J_{S C}$ to $V_{O C}$ & 19.8 & 1.01 & 63.4 & 12.7 & \\
\hline & & $V_{\mathrm{OC}}$ to $J_{\mathrm{SC}}$ & 19.6 & 1.03 & 67.2 & 13.6 & \\
\hline
\end{tabular}

The perovskite reference single-junction solar cells were fabricated in the superstrate configuration on a planar, commercial ITO coated glass. Instead of a $\mathrm{SnO}_{2} / \mathrm{IZO}$ top contact as implemented in the tandem architecture, they were finished with opaque BCP/Cu as a back electrode for higher reproducibility and comparison. ${ }^{37}$ The representative $J-V$ measurements are shown in Figure 4b. Three different hole contact layers (HTL) are analyzed and compared. First a single layer of PTAA; second, a single layer of $\mathrm{NiO}_{x}$ formed via ALD similarly as for the tandem solar cells; and third a $\mathrm{NiO}_{\mathrm{x}} /$ PTAA bilayer. Clearly, a single layer of PTAA outperforms the bare $\mathrm{NiO}_{x}$ hole contact. The PCE for PTAA based $\mathrm{HTL}$ is well above $17 \%$ and when utilizing $\mathrm{NiO}_{x} 13 \%$ are reached. The reason for such low performance of the $\mathrm{NiO}_{x}$ grown via ALD is likely due to a high interface recombination at the $\mathrm{NiO}_{x} /$ perovskite interface, reducing the $V_{\mathrm{Oc}}$. Compared to $\mathrm{NiO}_{x}$-only, the $\mathrm{NiO}_{x} /$ PTAA bilayer works surprisingly well, with only $1 \%$ absolute efficiency loss compared to PTAA as a single HTL. The loss seems to be due to the slightly reduced $\mathrm{FF}$ from increased series resistance induced by the additional PTAA. Overall, the difference in $\mathrm{V}_{\mathrm{OC}}$ between $\mathrm{NiO}_{x}$-only and $\mathrm{NiO}_{x}$ /PTAA bilayer is comparable between singlejunction and tandem devices. Interestingly, the FF of the $\mathrm{NiO}_{x}$-only device is better in the tandem configuration as compared to the single-junctions due to the fact that CIGSe bottom cell is limiting the photocurrent and thus dictating the tandem FF. The parameters from the $J-V$ characteristic from the corresponding subcells are also shown in Table 1. 
a)

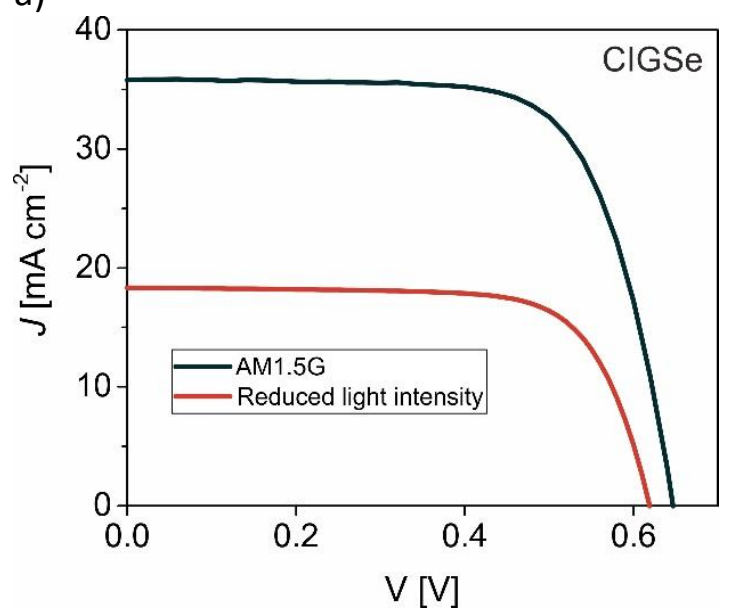

b)

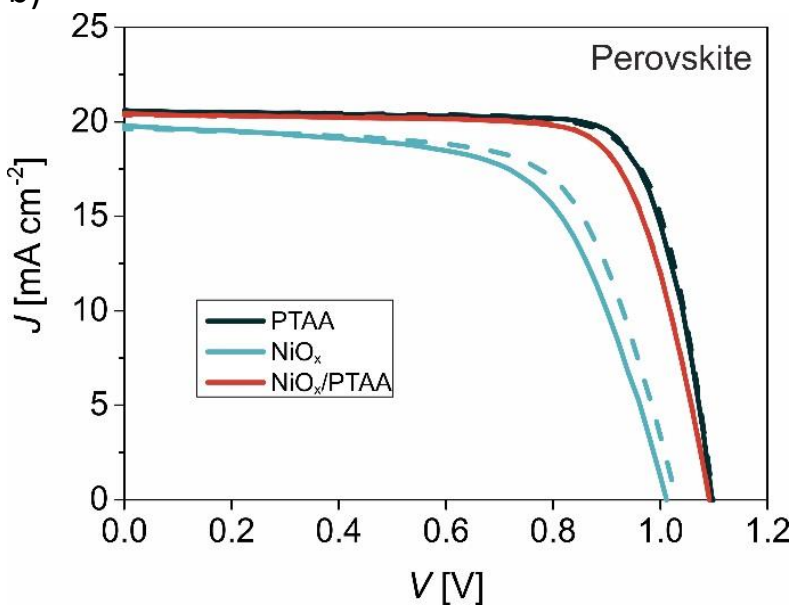

Figure 4: J-V characteristics of a) CIGSe single-junction reference under AM1.5G and reduced light intensity and b) perovskite single-junction reference cell with different HTLs: PTAA (black), NiO $\mathrm{x}_{x}$ (blue) and $\mathrm{NiO}_{x} / \mathrm{PTAA}$ (red) under AM1.5G. Solid lines show forward ( $J_{S C}$ to $V_{O C}$ ) scan and dashed lines reverse ( $V_{O C}$ to $J_{S C}$ ) scan direction. The performance parameters are stated in Table 1.

Finally, we analyze the measured $V_{O c}$ of the tandem cell in more detail by recording absolute hyperspectral photoluminescence (PL) image. This technique has recently been demonstrated to be an effective way of estimating the losses determining the Quasi-Fermi level splitting (QFLS) in single-junction solar cells. ${ }^{3}$ In the ideal case, the measured QFLS directly translates into $V_{O C}\left(V_{O C}=Q F L S / q\right)$, revealing the voltage potential of a solar cell device. Here, for the first time, this method is applied for monolithic tandem solar cells. When measuring the monolithic tandem solar cell, each of the subcells has to be excited separately, thus two independent measurements are required. In our case, we excited the perovskite subcell with $450 \mathrm{~nm}$ light and the CIGSe subcell with light of $850 \mathrm{~nm}$ wavelength. By using an excitation wavelength of $850 \mathrm{~nm}$ we can probe the photoluminescence properties of the bottom cell as this wavelength will not be absorbed by the top cell (see Figure $3 b$ ). The results in Figure 5 a show that the QFLS of the bottom cell is around $0.613 \mathrm{eV}$. This value fits well with the $V_{\text {oc }}$ of the CIGSe singlejunction device measured under reduced light intensity $(0.62 \mathrm{~V})$. The $V_{\text {OC }}$ of the reference CIGSe single-junction (Figure 4a) solar cell is $35 \mathrm{mV}$ larger, which however is also fully consistent with the QFLS measurement on the tandem, when the higher illumination level in the absence of the top cell is considered (see experimental section). This indicates that quite a significant voltage loss is induced in the bottom absorber layer by its incorporation into the tandem device architecture through being illuminated with lower intensity. Figure $5 b$ shows that the perovskite QFLS is $1.09 \mathrm{eV}$ which again fits well with the $V_{O C}$ of the reference perovskite device. This indicates that no significant voltage losses are added into the perovskite subcell by its implementation into the tandem architecture either, despite a nonflat surface of the substrate for spin-coating. Both subcells show great uniformity of the absorber layer over the active area of $\sim 0.8 \mathrm{~cm}^{2}$. Translated to voltage, the $V_{\text {oc }}$ of the tandem should be as high as $1.70 \mathrm{~V}$, which is $70 \mathrm{mV}$ lower than in the current world record perovskite/CIGSe monolithic tandem device. ${ }^{24}$ The difference might lie in a different top contact system and/or subcell absorber quality utilized here as compared to the work by Han et al. ${ }^{24}$ For our device, it means that in the actual $J-V$ measurement, $100 \mathrm{mV}$ are lost in the tandem device as compared to the sum of the QFLS. This indicates a limiting recombination loss at the subcells' interconnection/tunnel junction in the tandem or the transparent top 
contact. We propose that this is most likely due to the non-optimized $\mathrm{ZnO}$ recombination contact. Only with an efficient recombination contact with well aligned energy levels, we can assume that the QFLS of both subcells can be summed-up for the complete stack.

a)

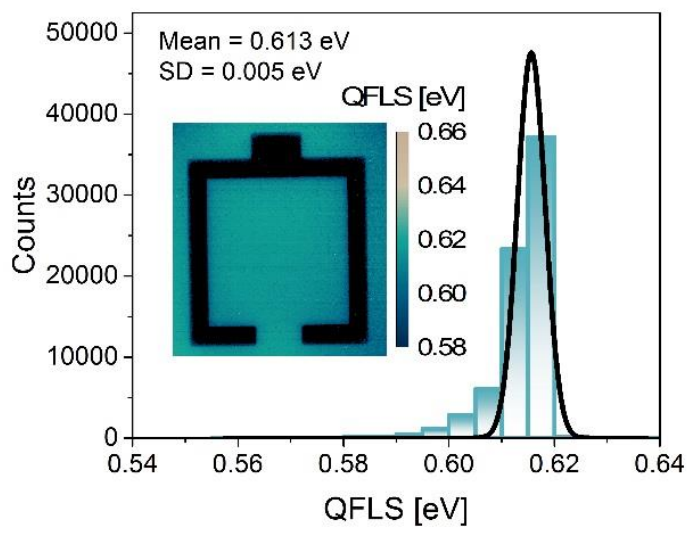

b)

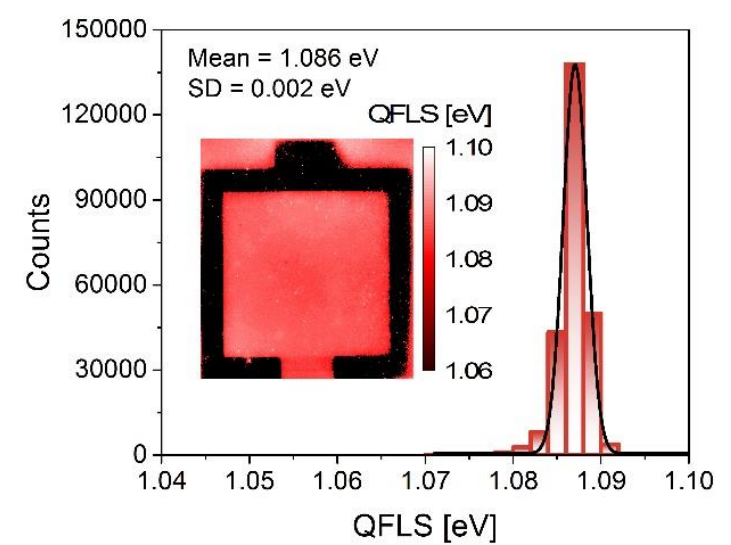

Figure 5: Quasi-Fermi level splitting (QFLS) maps and histogram obtained from absolute PL mapping of the perovskite/CIGSe tandem device: a) CIGSe bottom cell and b) perovskite top cell. From the histogram, the QFLS of $0.613 \mathrm{eV}$ for CIGSe and b) $1.086 \mathrm{eV}$ for the perovskite can be estimated.

To reach the predicted tandem efficiency potential of over $30 \%$ for this purely thin film tandem design, some improvements still need to be developed. First, the bilayer champion device is still limited by current mismatch between the individual subcells. Detailed optical simulations, similar to those in perovskite/silicon tandem devices ${ }^{6,11}$ are needed to enable optimal current generation and possible light management schemes for perovskite/CIGSe tandem devices. ${ }^{38}$ Secondly, the presented tandem solar cells are limited by $V_{\text {oc. }}$ In the tandem device the full $V_{\text {oc }}$ potential of the single-junction device was not reached, which indicates that the recombination layers could be limiting the $V_{\text {oc }}$. Moreover, improving the $\mathrm{NiO}_{x} /$ perovskite interface, implementing proper interlayers ${ }^{3}$ or another conformally grown hole transport layer, such as by self-assembled molecules $(\mathrm{SAMs})^{39}$ could be alternative strategies to improve the $V_{\text {oc. }}$

In conclusion, a highly efficient monolithic perovskite/CIGSe tandem device with a perovskite subcell deposited directly on top of a rough bottom CIGSe cell by implementing a bilayer p-type contact was presented. This double hole transport layer is formed by a conformally

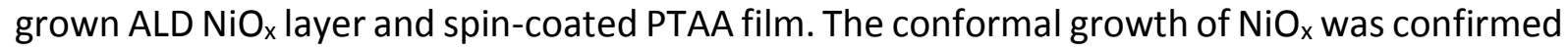
by TEM/EDX analysis, revealing a uniformly thick layer of $\mathrm{NiO}_{x}$ on both the peaks and valleys of the rough CIGSe substrate. On the other hand, indications that the spin-coated PTAA agglomerates in the valleys and uncovered substrate peaks were found, causing shunting of the device, thus highlighting the need for a conformal deposition on rough surfaces. With our conformal hole contact approach, shunting of the top cell, which is typical for perovskite solar cells on rough surfaces, was prevented. With that a stabilized tandem efficiency of $18 \%$ was reached for the $\mathrm{NiO}_{x}$ hole contact. Further utilizing the $\mathrm{NiO}_{x} /$ PTAA bilayer improved the resulting monolithic perovskite/CIGSe tandem solar cell to $21.6 \%$ PCE on $0.778 \mathrm{~cm}^{2}$ active area, stable over 10 minutes of maximum power point tracking. Optically, the fabricated champion device works very well, enabling high photocurrents similar to perovskite/silicon tandem devices. Absolute photoluminescence measurements of the tandem cell were also 
presented for the first time; the results showed the contribution of the subcells to the tandem $V_{\text {oc }}$, revealing that additional fine-tuning the interconnection layers between the two subcells might improve the tandem $V_{\text {oc }}$ further. Our results show a step towards efficient, true thin film monolithic perovskite/CIGSe tandem solar cells that are likely to enable the predicted efficiencies of over $30 \%$ in the near future.

\section{Experimental}

CIGSe bottom cell: The CIGSe subcell is fabricated in a substrate configuration on glass. First, $800 \mathrm{~nm}$ of molybdenum are sputtered as a back contact. The CIGSe absorber is deposited by thermal evaporation from elemental sources using a processing sequence based on the wellknown multi-stage process. ${ }^{40}$ In this process, an $(\mathrm{In}, \mathrm{Ga})_{2} \mathrm{Se}_{3}$ precursor is deposited at a substrate temperature of $300^{\circ} \mathrm{C}$ in the first stage, followed by the evaporation of $\mathrm{Cu}$ and $\mathrm{Se}$ at a substrate temperature of $530^{\circ} \mathrm{C}$ until the absorber becomes overall copper rich. The process is completed by the evaporation of $\mathrm{In}, \mathrm{Ga}$, and $\mathrm{Se}$ in the last stage to make the absorber copper poor again ( $\mathrm{CGI}=0.9, \mathrm{GGI}=0,3$ ). As it was shown in, ${ }^{18}$ the surface roughness of the CIGSe layer increases during all stages and it is thus important to keep the layer thickness as small as possible. The CdS layer is deposited by a wet-chemical process. Finally, $120 \mathrm{~nm}$ ITO was sputtered as a recombination contact for connecting both subcells.

The reference CIGSe was prepared in the same way as the bottom CIGSe cell, except for the top TCO. Instead of ITO, here $40 \mathrm{~nm}$ intrinsic $\mathrm{ZnO}$ and afterwards $110 \mathrm{~nm}$ Al doped $\mathrm{ZnO}$ were deposited. The cell was finished by a Ni-Al-Ni grid. The active area of the reference cell is $0.97 \mathrm{~cm}^{2}$.

Perovskite top cell: The fabricated perovskite subcells have an inverted ( $p-i-n)$ planar structure and a layer configuration of CIGSe substrate/ITO/NiO ${ }_{x} / \mathrm{PTAA} /$ Perovskite/ $\mathrm{C}_{60} / \mathrm{SnO}_{2} / \mathrm{IZO}$. The PTAA is poly [bis (4-phenyl) $(2,5,6-$ trimentlyphenyl) amine] and $\mathrm{IZO}$ is zinc doped indium oxide.

ALD NiO layers were deposited on top of the CIGSe substrates in a home-built ALD reactor, which is a high-vacuum system that is evacuated by a combination of a rotary and a turbomolecular pump to a base pressure of $\sim 10^{-6} \mathrm{mbar}$. The system has been extensively described in our previous work. ${ }^{41}$ After a pre-deposition oxygen plasma treatment $(100 \mathrm{~W})$ of 15 min, ALD NiO was processed using bis-methylcyclopentadienyl-nickel (( $\left.\mathrm{Ni}(\mathrm{MeCp})_{2}\right), 97 \%$, Sigma-Aldrich) as the precursor and $\mathrm{O}_{2}$ plasma as the co-reactant. The $\mathrm{Ni}(\mathrm{MeCp})_{2}$ was kept at $55{ }^{\circ} \mathrm{C}$ to ensure adequate vapor pressure and was dosed using Ar carrier gas through a delivery line heated to $75^{\circ} \mathrm{C}$. Each ALD cycle consisted of $\left.3 \mathrm{~s} \mathrm{Ni(MeCp}\right)_{2}$ dose, $4 \mathrm{~s}$ purge time, $3 \mathrm{~s} \mathrm{O}_{2}$ plasma exposure, and $1 \mathrm{~s}$ purge time. 350 ALD cycles were performed to obtain a final thickness of $9.5 \mathrm{~nm}$. The reactor walls were kept at $100^{\circ} \mathrm{C}$, and the substrate table was heated to $150{ }^{\circ} \mathrm{C}$. The details regarding the $\mathrm{NiO}_{x}$ process development including the saturation curves will be published elsewhere.

The $\mathrm{NiO}_{x}$ coated $\mathrm{CIGSe}$ substrates were used as prepared. All the perovskite layer deposition steps were conducted in a nitrogen atmosphere. The hole transport layer PTAA (Sigma Aldrich, $2 \mathrm{mg} / \mathrm{ml}$ in toluene) was deposited using spin-coating (4000 rpm for $30 \mathrm{~s}$ ) and annealed for $10 \mathrm{~min}$ at $100{ }^{\circ} \mathrm{C}$. The perovskite layer was prepared following the typical triple cation process 
and spun using a one-step solution process (4000 rpm for $35 \mathrm{~s}$ ). ${ }^{35} 25 \mathrm{~s}$ after the start of a spinning the ethyl acetate anti-solvent drop was utilized. The films were annealed at $100{ }^{\circ} \mathrm{C}$ for $1 \mathrm{~h}$. Afterwards, $20 \mathrm{~nm} \mathrm{C} 60$ (Sigma Aldrich, purity = 99.9\%) was thermally evaporated at a rate of 0.15 at $400{ }^{\circ} \mathrm{C}$. As a buffer layer for IZO sputtering, $20 \mathrm{~nm} \mathrm{SnO} 2$ was deposited via thermal ALD (Arradiance GEMStar) using tetrakis(dimethylamino)tin(IV) (TDMASn) and water as precursors, held at $60^{\circ} \mathrm{C}$ and without heating in a stainless steel container, respectively. IZO was deposited by RF sputtering from a target, consisting of $90 \% w t . \ln _{2} \mathrm{O}_{3}$ and $10 \% w t$. $\mathrm{ZnO}$. Afterwards, a $180 \mathrm{~nm}$ thick Ag metal frame was evaporated as a top contact, defining the active area of $0.81 \mathrm{~cm}^{2}$. Finally, a $120 \mathrm{~nm}$ LiF was evaporated as an anti-reflection coating.

For the reference cell, the evaporation of $23 \mathrm{~nm} \mathrm{C} 60$ was followed by evaporation of $8 \mathrm{~nm} \mathrm{BCP}$ (bathocuproine). The cells were finished by evaporating $100 \mathrm{~nm}$ copper through the shadow mask. The final active area is $0.16 \mathrm{~cm}^{2}$.

Device characterization: The current density-voltage $(J-V)$ measurements were performed under standard test conditions $\left(25^{\circ} \mathrm{C}\right.$, LED sun simulator, Wavelabs, class AAA), adjusted with a calibrated silicon reference cell (Fraunhofer ISE). The scan rate was $0.125 \mathrm{~V} \mathrm{~s}^{-1}$ with a voltage step of $10 \mathrm{mV}$. Measurements were carried out in air. For the tandem device measurements, a mask with a $0.778 \mathrm{~cm}^{2}$ area was used. During the measurements, the CIGSe tandems and single-junction sample were kept at $25{ }^{\circ} \mathrm{C}$. For the measurements of perovskite reference cells, however, an additional holder was used. Therefore the cooling was not as efficient; we estimate the $\mathrm{T}$ was in the range of $28-30^{\circ} \mathrm{C}$. The external quantum efficiency (EQE) was measured as a function of wavelength from 300 to $1200 \mathrm{~nm}$ with a step of $10 \mathrm{~nm}$ using a home built EQE system. When measuring the perovskite top cell, blue and red bias light were applied along with $0.5 \mathrm{~V}$ bias voltage. When measuring the CIGSe bottom cell blue bias light was applied along with $0.7 \mathrm{~V}$ bias voltage. The reflection was measured as a function of wavelength from 300 to $1200 \mathrm{~nm}$ with a step of $5 \mathrm{~nm}$ using an integrating sphere with a Perkin Elmer Lambda - 1050 UV/VIS/NIR spectrophotometer, calibrated with a white Spectralon.

Transmission Electron Microscopy (TEM): The TEM studies were performed using a probecorrected JEOL ARM 200F TEM, operated at $200 \mathrm{kV}$, equipped with a $100 \mathrm{~mm}^{2}$ Centurion SDD detector for EDX elemental mapping. Cross-sectional TEM sample preparation was performed using a Focused lon Beam (FIB) using a standard lift-out process.

Hyperspectral absolute photoluminescence imaging: The photoluminescence image detection was performed with a charge-coupled device (CCD) camera for the perovskite subcell and with a peltier-cooled InGaAs diode-array camera coupled with a liquid crystal tunable filter. The system was calibrated to absolute photon numbers in two steps in a similar way to the process described by Delamarre and colleagues. ${ }^{42}$ For this purpose an infrared laser diode and a spectrally calibrated halogen lamp were coupled to an integrating sphere. Excitation for the PL imaging measurements was performed with two $450 \mathrm{~nm}$ LEDs for the perovskite subcell and with an $850 \mathrm{~nm}$ LED for the excitation of the CIGSe subcell. The excitation intensities of the $450 \mathrm{~nm}$ and $850 \mathrm{~nm}$ LEDs were $1.6 \times 10^{21}$ photons $\mathrm{m}^{-2} \mathrm{~s}^{-1}$ and $7.5 \mathrm{x}$ $10^{20}$ photons $\mathrm{m}^{-2} \mathrm{~s}^{-1}$ respectively.

Assuming a step-like absorptivity of the absorber layers and no parasitic absorption of the contact layers an absorbed photon flux $\sim 1.6 \times 10^{21}$ photons $\mathrm{m}^{-2} \mathrm{~s}^{-1}$ for the top cell $\left(E_{g}=1.6 \mathrm{eV}\right)$ 
and $\sim 1.2 \times 10^{21}$ photons $\mathrm{m}^{-2} \mathrm{~s}^{-1}$ is calculated for the bottom cell $\left(E_{g}=1.1 \mathrm{eV}\right)$ in a tandem cell with AM1.5 illumination. However, in this study, due to experimental restrictions, the bottom cell was illuminated with $\sim 7.5 \times 10^{20}$ photons $\mathrm{m}^{-2} \mathrm{~s}^{-1}$ at $850 \mathrm{~nm}$. Consequently, assuming an ideality factor $\left(n_{\text {rad }}\right)$ of 1.4 for CIGSe, ${ }^{43,44}$ the AM1.5-equivalent QFLS for the bottom cell in the tandem device is increased by $17 \mathrm{meV}$ to a value of $0.61 \mathrm{eV}$ using $q \cdot \Delta V_{o c}=n_{\text {rad }}$. $k_{B} T \ln \left(\frac{1.2 \cdot 10^{21}}{7.5 \cdot 10^{20}}\right)$. Considering the bottom cell independent of the tandem device, an absorption of $\sim 2.8 \times 10^{21}$ photons $\mathrm{m}^{-2} \mathrm{~s}^{-1}$ is expected under AM1.5 conditions, such that in this case the AM1.5G equivalent QFLS is calculated to $0.644 \mathrm{eV}$, which agrees closely with the unfiltered $V_{\text {oc }}$ measurement on the single-junction CIGSe solar cell.

\section{Acknowledgement}

The authors acknowledge the funding by the German Federal Ministry of Education and Research (BMBF) via program "Materialforschung fuer die Energiewende" (grant no. 03SF0540) and by the German Federal Ministry of Economics and Technology (BMWi) through the speedCIGS (grant no. 0324095D) and EFFCIS project (grant no. 0324076D). S. Braunger gratefully acknowledges the Alexander von Humboldt Foundation for a Feodor Lynen Return Fellowship. The work of D. Koushik is supported by the Light Management in New Photovoltaic Materials (LMPV) research program of the Netherlands Organization for Scientific Research (NWO). Solliance and the Dutch province of Noord-Brabant are acknowledged for funding the TEM facility. Dr. B. Barconez (TU/e) prepared the focused ion beam (FIB) lift-out TEM samples.

Supporting Information Available: additional TEM/EDX images of bilayer on a rough CIGSe substrate, maximum power point tracking, $J-V$, reflection and transmission data of semitransparent perovskite devices.

\section{References}

(1) Unger, E. L.; Kegelmann, L.; Suchan, K.; Sörell, D.; Korte, L.; Albrecht, S. Roadmap and Roadblocks for the Band Gap Tunability of Metal Halide Perovskites. J. Mater. Chem. A 2017, 5 (23), 11401-11409. https://doi.org/10.1039/C7TA00404D.

(2) Sutter-Fella, C. M.; Li, Y.; Amani, M.; Ager, J. W.; Toma, F. M.; Yablonovitch, E.; Sharp, I. D.; Javey, A. High Photoluminescence Quantum Yield in Band Gap Tunable Bromide Containing Mixed Halide Perovskites. Nano Lett. 2016, 16 (1), 800-806.

https://doi.org/10.1021/acs.nanolett.5b04884.

(3) Stolterfoht, M.; Wolff, C. M.; Márquez, J. A.; Zhang, S.; Hages, C. J.; Rothhardt, D.; Albrecht, S.; Burn, P. L.; Meredith, P.; Unold, T.; et al. Visualization and Suppression of Interfacial Recombination for High-Efficiency Large-Area Pin Perovskite Solar Cells. Nat. Energy 2018, 1. https://doi.org/10.1038/s41560-018-0219-8.

(4) Luo, D.; Yang, W.; Wang, Z.; Sadhanala, A.; Hu, Q.; Su, R.; Shivanna, R.; Trindade, G. F.; Watts, J. F.; Xu, Z.; et al. Enhanced Photovoltage for Inverted Planar Heterojunction Perovskite Solar Cells. Science 2018, 360 (6396), 1442-1446. https://doi.org/10.1126/science.aap9282.

(5) Green, M. A.; Hishikawa, Y.; Dunlop, E. D.; Levi, D. H.; Hohl-Ebinger, J.; Yoshita, M.; Ho-Baillie, A. W. Y. Solar Cell Efficiency Tables (Version 53). Prog. Photovolt. Res. Appl. 2019, 27 (1), 3-12. https://doi.org/10.1002/pip.3102.

(6) Jäger, K.; Korte, L.; Rech, B.; Albrecht, S. Numerical Optical Optimization of Monolithic Planar Perovskite-Silicon Tandem Solar Cells with Regular and Inverted Device Architectures. Opt. Express 2017, 25 (12), A473-A482. https://doi.org/10.1364/OE.25.00A473. 
(7) Hörantner, M. T.; Leijtens, T.; Ziffer, M. E.; Eperon, G. E.; Christoforo, M. G.; McGehee, M. D.; Snaith, H. J. The Potential of Multijunction Perovskite Solar Cells. ACS Energy Lett. 2017, 2 (10), 2506-2513. https://doi.org/10.1021/acsenergylett.7b00647.

(8) Shen, H.; Duong, T.; Peng, J.; Jacobs, D.; Wu, N.; Gong, J.; Wu, Y.; Karuturi, S. K.; Fu, X.; Weber, K.; et al. Mechanically-Stacked Perovskite/CIGS Tandem Solar Cells with Efficiency of $23.9 \%$ and Reduced Oxygen Sensitivity. Energy Environ. Sci. 2018, 11 (2), 394-406. https://doi.org/10.1039/C7EE02627G.

(9) Albrecht, S.; Saliba, M.; Baena, J. P. C.; Lang, F.; Kegelmann, L.; Mews, M.; Steier, L.; Abate, A.; Rappich, J.; Korte, L.; et al. Monolithic Perovskite/Silicon-Heterojunction Tandem Solar Cells Processed at Low Temperature. Energy Environ. Sci. 2016, 9 (1), 81-88. https://doi.org/10.1039/C5EE02965A.

(10) Werner, J.; Niesen, B.; Ballif, C. Perovskite/Silicon Tandem Solar Cells: Marriage of Convenience or True Love Story? - An Overview. Adv. Mater. Interfaces 2017, 5 (1), 1700731. https://doi.org/10.1002/admi.201700731.

(11) Jošt, M.; Köhnen, E.; Morales-Vilches, A. B.; Lipovšek, B.; Jäger, K.; Macco, B.; Al-Ashouri, A.; Krč, J.; Korte, L.; Rech, B.; et al. Textured Interfaces in Monolithic Perovskite/Silicon Tandem Solar Cells: Advanced Light Management for Improved Efficiency and Energy Yield. Energy Environ. Sci. 2018, 11 (12), 3511-3523. https://doi.org/10.1039/C8EE02469C.

(12) Sahli, F.; Werner, J.; Kamino, B. A.; Bräuninger, M.; Monnard, R.; Paviet-Salomon, B.; Barraud, L.; Ding, L.; Leon, J. J. D.; Sacchetto, D.; et al. Fully Textured Monolithic Perovskite/Silicon Tandem Solar Cells with 25.2\% Power Conversion Efficiency. Nat. Mater. 2018, 1. https://doi.org/10.1038/s41563-018-0115-4.

(13) Contreras, M. A.; Mansfield, L. M.; Egaas, B.; Li, J.; Romero, M.; Noufi, R.; Rudiger-Voigt, E.; Mannstadt, W. Wide Bandgap Cu(In,Ga)Se2 Solar Cells with Improved Energy Conversion Efficiency. Prog. Photovolt. Res. Appl. 2012, 20 (7), 843-850. https://doi.org/10.1002/pip.2244.

(14) Kranz, L.; Abate, A.; Feurer, T.; Fu, F.; Avancini, E.; Löckinger, J.; Reinhard, P.; Zakeeruddin, S. M.; Grätzel, M.; Buecheler, S.; et al. High-Efficiency Polycrystalline Thin Film Tandem Solar Cells. J. Phys. Chem. Lett. 2015, 6 (14), 2676-2681. https://doi.org/10.1021/acs.jpclett.5b01108.

(15) Fu, F.; Feurer, T.; Jäger, T.; Avancini, E.; Bissig, B.; Yoon, S.; Buecheler, S.; Tiwari, A. N. LowTemperature-Processed Efficient Semi-Transparent Planar Perovskite Solar Cells for Bifacial and Tandem Applications. Nat. Commun. 2015, 6, 8932. https://doi.org/10.1038/ncomms9932.

(16) Fu, F.; Feurer, T.; Weiss, T. P.; Pisoni, S.; Avancini, E.; Andres, C.; Buecheler, S.; Tiwari, A. N. High-Efficiency Inverted Semi-Transparent Planar Perovskite Solar Cells in Substrate Configuration. Nat. Energy 2017, 2 (1), 16190. https://doi.org/10.1038/nenergy.2016.190.

(17) Jehl, Z.; Bouttemy, M.; Lincot, D.; Guillemoles, J. F.; Gerard, I.; Etcheberry, A.; Voorwinden, G.; Powalla, M.; Naghavi, N. Insights on the Influence of Surface Roughness on Photovoltaic Properties of State of the Art Copper Indium Gallium Diselenide Thin Films Solar Cells. J. Appl. Phys. 2012, 111 (11), 114509. https://doi.org/10.1063/1.4721648.

(18) Heinemann, M. D.; Mainz, R.; Österle, F.; Rodriguez-Alvarez, H.; Greiner, D.; Kaufmann, C. A.; Unold, T. Evolution of Opto-Electronic Properties during Film Formation of Complex Semiconductors. Sci. Rep. 2017, 7, 45463. https://doi.org/10.1038/srep45463.

(19) Yang, W. S.; Park, B.-W.; Jung, E. H.; Jeon, N. J.; Kim, Y. C.; Lee, D. U.; Shin, S. S.; Seo, J.; Kim, E. K.; Noh, J. H.; et al. lodide Management in Formamidinium-Lead-Halide-based Perovskite Layers for Efficient Solar Cells. Science 2017, 356 (6345), 1376-1379. https://doi.org/10.1126/science.aan2301.

(20) Todorov, T.; Gershon, T.; Gunawan, O.; Lee, Y. S.; Sturdevant, C.; Chang, L.-Y.; Guha, S. Monolithic Perovskite-CIGS Tandem Solar Cells via In Situ Band Gap Engineering. Adv. Energy Mater. 2015, 5 (23), n/a-n/a. https://doi.org/10.1002/aenm.201500799. 
(21) Meng, L.; You, J.; Guo, T.-F.; Yang, Y. Recent Advances in the Inverted Planar Structure of Perovskite Solar Cells. Acc. Chem. Res. 2016, 49 (1), 155-165.

https://doi.org/10.1021/acs.accounts.5b00404.

(22) Jang, Y. H.; Lee, J. M.; Seo, J. W.; Kim, I.; Lee, D.-K. Monolithic Tandem Solar Cells Comprising Electrodeposited CuInSe2 and Perovskite Solar Cells with a Nanoparticulate ZnO Buffer Layer. J. Mater. Chem. A 2017, 5 (36), 19439-19446. https://doi.org/10.1039/C7TA06163C.

(23) Uhl, A. R.; Rajagopal, A.; Clark, J. A.; Murray, A.; Feurer, T.; Buecheler, S.; Jen, A. K.-Y.; Hillhouse, H. W. Solution-Processed Low-Bandgap Culn(S,Se)2 Absorbers for High-Efficiency Single-Junction and Monolithic Chalcopyrite-Perovskite Tandem Solar Cells. Adv. Energy Mater. $O$ (0), 1801254. https://doi.org/10.1002/aenm.201801254.

(24) Han, Q.; Hsieh, Y.-T.; Meng, L.; Wu, J.-L.; Sun, P.; Yao, E.-P.; Chang, S.-Y.; Bae, S.-H.; Kato, T.; Bermudez, V.; et al. High-Performance Perovskite/Cu(In,Ga)Se2 Monolithic Tandem Solar Cells. Science 2018, 361 (6405), 904-908. https://doi.org/10.1126/science.aat5055.

(25) Aydin, E.; Troughton, J.; De Bastiani, M.; Ugur, E.; Sajjad, M.; Alzahrani, A.; Neophytou, M.; Schwingenschlögl, U.; Laquai, F.; Baran, D.; et al. Room-Temperature Sputtered Nanocrystalline Nickel Oxide as Hole Transport Layer for P-i-n Perovskite Solar Cells. ACS Appl. Energy Mater. 2018. https://doi.org/10.1021/acsaem.8b01263.

(26) Tsai, H.; Asadpour, R.; Blancon, J.-C.; Stoumpos, C. C.; Durand, O.; Strzalka, J. W.; Chen, B.; Verduzco, R.; Ajayan, P. M.; Tretiak, S.; et al. Light-Induced Lattice Expansion Leads to HighEfficiency Perovskite Solar Cells. Science 2018, 360 (6384), 67-70. https://doi.org/10.1126/science.aap8671.

(27) Xu, X.; Ma, C.; Cheng, Y.; Xie, Y.-M.; Yi, X.; Gautam, B.; Chen, S.; Li, H.-W.; Lee, C.-S.; So, F.; et al. Ultraviolet-Ozone Surface Modification for Non-Wetting Hole Transport Materials Based Inverted Planar Perovskite Solar Cells with Efficiency Exceeding 18\%. J. Power Sources 2017, 360, 157-165. https://doi.org/10.1016/j.jpowsour.2017.06.013.

(28) Stolterfoht, M.; Wolff, C. M.; Amir, Y.; Paulke, A.; Toro, L. P.; Caprioglio, P.; Neher, D. Approaching the Fill Factor Shockley Queisser Limit in Stable, Dopant-Free Triple Cation Perovskite Solar Cells. Energy Environ. Sci. 2017. https://doi.org/10.1039/C7EE00899F.

(29) Heo, J. H.; Han, H. J.; Kim, D.; Ahn, T. K.; Im, S. H. Hysteresis-Less Inverted CH3NH3Pbl3 Planar Perovskite Hybrid Solar Cells with 18.1\% Power Conversion Efficiency. Energy Environ. Sci. 2015, 8 (5), 1602-1608. https://doi.org/10.1039/C5EE00120J.

(30) Braunger, S.; Mundt, L. E.; Wolff, C. M.; Mews, M.; Rehermann, C.; Jošt, M.; Tejada, A.; Eisenhauer, D.; Becker, C.; Guerra, J. A.; et al. CsxFA1-xPb(I1-yBry)3 Perovskite Compositions: The Appearance of Wrinkled Morphology and Its Impact on Solar Cell Performance. J. Phys. Chem. C 2018, 122 (30), 17123-17135. https://doi.org/10.1021/acs.jpcc.8b06459.

(31) Wang, Y.; Wenisch, R.; Schlatmann, R.; Lauermann, I. Inorganic Materials as Hole Selective Contacts and Intermediate Tunnel Junction Layer for Monolithic Perovskite-CIGSe Tandem Solar Cells. Adv. Energy Mater. 2018, 8 (30), 1801692. https://doi.org/10.1002/aenm.201801692.

(32) Seo, S.; Park, I. J.; Kim, M.; Lee, S.; Bae, C.; Jung, H. S.; Park, N.-G.; Kim, J. Y.; Shin, H. An UltraThin, Un-Doped NiO Hole Transporting Layer of Highly Efficient (16.4\%) Organic-inorganic Hybrid Perovskite Solar Cells. Nanoscale 2016, 8 (22), 11403-11412. https://doi.org/10.1039/C6NR01601D.

(33) Zhao, B.; Lee, L. C.; Yang, L.; Pearson, A. J.; Lu, H.; She, X.-J.; Cui, L.; Zhang, K. H. L.; Hoye, R. L. Z.; Karani, A.; et al. In Situ Atmospheric Deposition of Ultrasmooth Nickel Oxide for Efficient Perovskite Solar Cells. ACS Appl. Mater. Interfaces 2018, 10 (49), 41849-41854. https://doi.org/10.1021/acsami.8b15503.

(34) Brenes, R.; Guo, D.; Osherov, A.; Noel, N. K.; Eames, C.; Hutter, E. M.; Pathak, S. K.; Niroui, F.; Friend, R. H.; Islam, M. S.; et al. Metal Halide Perovskite Polycrystalline Films Exhibiting Properties of Single Crystals. Joule 2017, 1 (1), 155-167. https://doi.org/10.1016/j.joule.2017.08.006. 
(35) Saliba, M.; Matsui, T.; Seo, J.-Y.; Domanski, K.; Correa-Baena, J.-P.; Nazeeruddin, M. K.; Zakeeruddin, S. M.; Tress, W.; Abate, A.; Hagfeldt, A.; et al. Cesium-Containing Triple Cation Perovskite Solar Cells: Improved Stability, Reproducibility and High Efficiency. Energy Environ. Sci. 2016, 9 (6), 1989-1997. https://doi.org/10.1039/C5EE03874J.

(36) Jošt, M.; Albrecht, S.; Kegelmann, L.; Wolff, C. M.; Lang, F.; Lipovšek, B.; Krč, J.; Korte, L.; Neher, D.; Rech, B.; et al. Efficient Light Management by Textured Nanoimprinted Layers for Perovskite Solar Cells. ACS Photonics 2017, 4 (5), 1232-1239. https://doi.org/10.1021/acsphotonics.7b00138.

(37) Saliba, M.; Correa-Baena, J.-P.; Wolff, C. M.; Stolterfoht, M.; Phung, N.; Albrecht, S.; Neher, D.; Abate, A. How to Make over 20\% Efficient Perovskite Solar Cells in Regular (N-i-p) and Inverted (P-i-n) Architectures. Chem. Mater. 2018, 30 (13), 4193-4201. https://doi.org/10.1021/acs.chemmater.8b00136.

(38) Mantilla-Perez, P.; Feurer, T.; Correa-Baena, J.-P.; Liu, Q.; Colodrero, S.; Toudert, J.; Saliba, M.; Buecheler, S.; Hagfeldt, A.; Tiwari, A. N.; et al. Monolithic CIGS-Perovskite Tandem Cell for Optimal Light Harvesting without Current Matching. ACS Photonics 2017, 4 (4), 861-867. https://doi.org/10.1021/acsphotonics.6b00929.

(39) Magomedov, A.; Al-Ashouri, A.; Kasparavičius, E.; Strazdaite, S.; Niaura, G.; Jošt, M.; Malinauskas, T.; Albrecht, S.; Getautis, V. Self-Assembled Hole Transporting Monolayer for Highly Efficient Perovskite Solar Cells. Adv. Energy Mater. 0 (0), 1801892. https://doi.org/10.1002/aenm.201801892.

(40) Repins, I.; Contreras, M. A.; Egaas, B.; DeHart, C.; Scharf, J.; Perkins, C. L.; To, B.; Noufi, R. 19.9\%-Efficient ZnO/CdS/CulnGaSe2 Solar Cell with 81.2\% Fill Factor. Prog. Photovolt. Res. Appl. 2008, 16 (3), 235-239. https://doi.org/10.1002/pip.822.

(41) Heil, S. B. S.; Langereis, E.; Roozeboom, F.; Sanden, M. C. M. van de; Kessels, W. M. M. LowTemperature Deposition of TiN by Plasma-Assisted Atomic Layer Deposition. J. Electrochem. Soc. 2006, 153 (11), G956-G965. https://doi.org/10.1149/1.2344843.

(42) Delamarre, A.; Lombez, L.; Guillemoles, J. F. Contactless Mapping of Saturation Currents of Solar Cells by Photoluminescence. Appl. Phys. Lett. 2012, 100 (13), 131108. https://doi.org/10.1063/1.3697704.

(43) Gunawan, O.; Gokmen, T.; Mitzi, D. B. Suns- VOC Characteristics of High Performance Kesterite Solar Cells. J. Appl. Phys. 2014, 116 (8), 84504. https://doi.org/10.1063/1.4893315.

(44) Rau, U.; Blank, B.; Müller, T. C. M.; Kirchartz, T. Efficiency Potential of Photovoltaic Materials and Devices Unveiled by Detailed-Balance Analysis. Phys. Rev. Appl. 2017, 7 (4), 44016. https://doi.org/10.1103/PhysRevApplied.7.044016. 